\title{
Interview with Mr. Shigeru Kawasaki
}

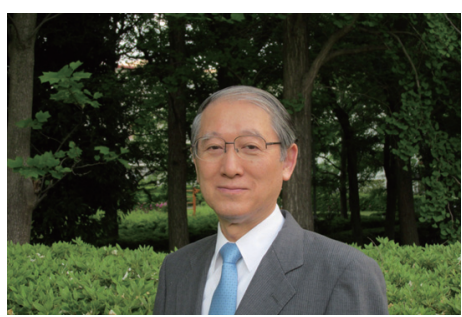

Mr. Shigeru Kawasaki is the 14th and current president of the IAOS, the first Japanese to hold this title. Currently a professor at Nihon University, he is the former Director General of the Statistics Bureau of Japan where he had a distinguished career. He has had many international experiences in the field of official statistics. He served as chairperson of the East Asian Statistical Conference, chairperson of the Population Census Conference, and chair of the session of the United Nations Statistical Commission. He also worked for three years in New York in the United Nations Statistics Division.

In the interview, Mr. Kawasaki talks about growing up in Japan and the paths that led him to a career in official statistics. The development of statistics in Japan, including the impact of Edward Deming, is also described. Mr. Kawasaki discusses the importance of international collaborations and the sharing of experiences globally to ensure that the field continues to grow and evolve. Official statistics must be reliable and of the highest quality. He concludes the interview by sharing his vision for the IAOS and the SJIAOS and appeals to the membership to become involved in all aspects of official statistics.

Interviewer: Thank you so much for allowing us to interview you. Let us start at the very beginning and go back to your childhood. What was it like growing up in your country after World War II?

Thank you very much for giving me an opportunity to speak about myself and my views. I was born in 1951 in Hiroshima, Japan. That was six years after the end of WW II. Many people, especially in foreign countries, ask me about Hiroshima and how it was like growing up in a city that was affected by the bomb. I have some relatives who survived the bombing, and I remember hearing horrifying stories in those days from an uncle. Also, in the civics classes at school, we learned much about the importance of keeping peace in the world, not just about the bombing but also the whole war. But as the city was rapidly reconstructed, I grew up without seeing the scenes of the aftermath very much.

What I remember from my childhood is that Japan was experiencing very rapid economic and social changes; it was a period of rapid economic growth, a period of economic recovery.

One of the symbolic events from my childhood was the Tokyo Olympics, the 1964 Summer Olympics. We were all excited about the big international event. I am fortunate that I will probably be able to see another Tokyo Olympics in 2020 in my lifetime. I am really looking forward to it.

Along with the Olympics, many new things were introduced in our life, the 'bullet train', for example. The Japanese bullet train, the Shinkansen, introduced modern high-speed rail services to the world in 1964. The first line ran from Tokyo to Osaka at $210 \mathrm{~km} / \mathrm{h}$, the world's highest speed in those days, and it reduced the travel time from 6 hours to 3 hours. Also, broadcast of color TV became popular, and many families began to purchase new TV sets to enjoy the Olympic Games in color. These are some of the memorable things that happened in my childhood.

Interviewer: Looking back to our childhoods, we often find that a particular event or person had an impact on our later years. Did a particular person or event shape you into the person you are today?

It is difficult to give a single event or person. But I think some events had a strong impact on me and made me start thinking about the world. I want to give two events that I remember in particular.

One is the news of the assassination of John F. Kennedy in 1963. That was just one year before the Tokyo Olympics. I got the shocking news, when my family and I were watching television in the morning 
of November 23. We had gathered in front of the TV, because on that day the first experimental TV broadcast through the communication satellite above the Pacific Ocean between the United States and Japan occurred, and we were all curious. Nowadays, telecommunication through satellites is so common, and not many people would be interested or excited about it, but on that day it was supposed to be an historical moment for telecommunication. We were expecting some interesting news on the screen, but all of a sudden the tragic news of the assassination came. That was really unbelievable. The broadcast made me feel the outside world much closer to me than before. I felt the world was not so secure and peaceful. I became strongly interested in the world and foreign countries. I was in the 6th grade in elementary school.

Another important event for me was my experience as a foreign exchange student to the U.S. from 1969 to 1970 . There is a program called American Field Service (AFS), which provides opportunities for high school students in many countries of the world to go to the United States for one year, staying with American families. I was fortunate to be one of the students selected to represent Japan. There were about 120 Japanese students in the program in that year.

I lived in Torrance, California, a southern suburb of Los Angeles, and spent my senior year there, staying with a host family. At the end of my stay, I was graduated, participating in the graduation ceremony with caps and gowns, which was quite different from Japan. I am really grateful to my host family for accepting me as a new family member.

It was a wonderful and rewarding experience. I made friends with many people there and lived in a different culture. Nowadays, Japan is quite westernized, but in those days, it was a different period. It was interesting to learn what I studied in Japan again, this time in English. So, it was also a very good opportunity to learn the language. However, I still find English difficult. So I hope I am doing well in this interview.

Interviewer: What stands out in your mind about your time in California as new experiences? What are some of the cultural differences you remember observing back then?

It was rather strange that the American life style didn't surprise me very much, because we could see many American shows and family dramas on Japanese television. So, it was quite amusing to me that everything I saw in California was just like what I saw on TV back in Japan. The only difference was that everyone spoke English, and there was no dubbing into Japanese as on Japanese TV.

Culturally speaking, I thought the style of communication was quite different. An average Japanese in those days was brought up to be quiet and modest, not to oppose others too much. If you have a different opinion from someone else, you would express it very mildly. But I found it was not like that in the United States. In the new environment, I felt I really had to speak directly, and speak up. Otherwise, people wouldn't listen to me, or wouldn't even think I was there. That was a new experience for me. Even now, I feel gaps in communication style sometimes, as it's not easy for me to change my habits. So, when I communicate with foreign people, I have to switch the channels in my brain from Japanese to English, not just the languages.

As I look back, living in a foreign country was a good opportunity for me to learn about my own country from the outside. People asked me many questions about Japan, and I had to give some answers, as I didn't feel like saying "I don't know." I tried to learn more about my own country, and explain it in my own words. Through such exchanges, I also learned about the perception and knowledge of American people about Japan, sometimes quite deep knowledge, other times misunderstanding. I didn't feel too bad about misunderstanding about Japan, because I might have also misunderstood Americans or people of other countries without knowing them. I thought understanding a foreign country is a very difficult process, needing a long time.

As the AFS Program invited students from all over the world, I could also make friends with students of other countries of my age, and could hear their views about my country. For example, I had friends from Vietnam, Panama, Jordan, and Australia, to name a few. Also, in my high school, I was not the only foreign student. There were classmates from Mexico and Cuba, and we became good friends too. I could actually learn about their countries and pick up some Spanish. All in all, the one year that I spent in California gave me a wonderful experience to learn and think about myself and different countries and cultures.

Interviewer: Think back to the time period when you were in California. It was 1969. Do you remember observing anything related to the American Civil Rights Movements? Also, around that time, at Berkeley, for example, they had the protests against the Vietnam War. What did you think about all that? 
Yes. You are right. It was an interesting time to be in California. I don't remember observing the Civil Rights Movement too well. But I was quite impressed that the younger generation was very actively speaking up about politics, especially the war in Vietnam. It was a period of hippies, Woodstock, and Easy Rider. I saw the movies with my friends in those days. I didn't understand them too well, but I at least got the feeling. There was a draft system in the United States and some young men burned their draft cards as a protest. As there was no draft system in Japan, and not now either, I was rather sympathetic to my American friends who might have to go to the war, if they were drafted. A lot of political debates were going on at that time.

Aside from political movements, I do remember one adventure in my school days there. Once I went across the border to Mexico without a passport. A group of us got together in a car. Back then, Americans did not have to bring their passports to cross the border to Mexico, so I just joined the group, forgetting about my nationality. We curiously drove around in Tijuana, Mexico, and bought some soft drinks. I was surprised to see the price of Coke was almost half or less than on the other side of the national border. As we were to go back, I found I didn't have my passport, and I started worrying that I might not be allowed to re-enter the U.S. My friends and I all decided that I should pretend to be a Japanese-American, if I was asked at the gate. It worked!

Interviewer: How did you get interested in statistics and mathematics? Actually, in the beginning you were more into math than statistics.

Yes. I was not strongly interested in statistics even in the university. Instead, I had liked mathematics and science very much since childhood. I still like it. This is probably because of my father's influence. He liked math and science very much, too. He was an elementary school teacher. He used to give me many numerical or geometrical puzzles, and told me about many interesting scientific phenomena and discoveries.

Before entering the university, I was hoping to become a mathematician or a physicist. However, during my university days, I became more interested in applying math to economic and social phenomena. In 1973, two years before my graduation, I read a report entitled "The Limits to Growth' 1 compiled by some

\footnotetext{
${ }^{1}$ Translated into Japanese from the original English version: Donella Meadows et al. (1972) "The Limits to Growth" Universe Books.
}

researchers of the Club of Rome. This book gave a prediction of mankind and the earth based on computerized simulations about human activities and nature. The main point of the prediction was that the economic growth of the world would reach a peak within one hundred years if the current economic and social trends, such as industrialization, population increase and natural resource consumption, continued, and that the most likely outcome would be an abrupt reduction of population and industrial output.

It was very shocking for the Japanese in those days. At the time, there was a severe oil crisis because of the war in the Middle East, and people were very concerned about the sustainability of energy resources. Environmental pollution was spreading in the country. This report was perceived realistically, and gave a very strong caution to Japanese society. It was just like the climate change report of the IPCC (Intergovernmental Panel on Climate Change) nowadays.

I traced the simulations in the report and other related materials. The prediction was based on a large number of equations employing many variables such as population, industrial production, food production, capital, natural resource reserves, etc. I thought it was not a very difficult model, although it was quite complex because of the large number of equations. I thought I might be able to make similar predictions more specific to Japan, if I could modify the model and use some other assumptions. I did my own research and got some results. After making my own simulations, I recognized that gathering reliable background data was quite a difficult task. I found the data they used didn't seem to be too reliable. There were many countries lacking the data, especially developing countries. Without having reliable data from all countries, the global figures wouldn't be too reliable. Also, many assumptions seemed to be quite arbitrary, and by changing the assumptions, the results changed very much. In the end, I became quite skeptical about the Club of Rome report.

After such an experience, I thought it very important to get reliable data. I doubted if it would be worthwhile predicting the future with arbitrary assumptions without reliable data. I became more interested in production of reliable statistics. That is how I got interested in official statistics. Fortunately, I found a job at the Prime Minister's Office to which the Statistics Bureau belonged in those days. I happily started working there. This was the beginning of my interest in official statistics. 
Interviewer: What were some of the international assignments you worked on early in your career?

My first assignment at the Statistics Bureau was to develop the systems for the Consumer Price Index and the Household Income and Expenditure Survey. There was a close relationship between my assignment and the work that I was to do at the United Nations (UN). Thanks to this relationship, I was seconded to the UN to work for the International Comparison Project (ICP) from 1978 to 1981.

The opportunity of getting a job at the UN came in late 1977. I worked on a short report of hedonic regression on house rent and automobile prices in Japan to be submitted to the UNICP. The UNICP is a project to estimate the purchasing power parities (PPP) of different currencies and to compare GDP across countries in real terms. In the mid-1970s, about 30 countries participated, and Japan was one of them. Nowadays, statistics on PPP are commonly available for international comparisons of GDP. But in those days, there were theories about PPP, but providing statistics of PPP was still at the stage of methodological development. Nobody gathered and compiled the basic data needed for computation of PPP on a global scale, and statistics of PPP were available only in a limited scale and on an experimental basis.

The ICP was originally initiated as a project of the University of Pennsylvania by three professors: Irving Kravis, Robert Summers, and Alan Heston. My ICP colleagues used to call them the "three wise men of the ICP." Because of the nature of the enormous task of collecting reliable and detailed price data and national accounts statistics from all over the world, the project was established in 1968 as a joint undertaking between the University and the United Nations Statistical Office (the former name of the UN Statistics Division) 2 When I was working at the UN, the ICP was a part of the UN Statistical Office. The ICP is now continued by the World Bank as the International Comparison Program involving almost 200 countries.

One essential field of the ICP work was to compare prices of many goods and services across countries. But comparing complex products and services, such as house rent and automobile prices, was a difficult task. What they did was to estimate 'hedonic equations' using regression methods, explaining the prices by the specifications of the products. In 1977, I did the esti-

\footnotetext{
${ }^{2}$ The name of the United Nations Statistical Office was changed to the United Nations Statistics Division in 1994.
}

mation, and wrote a report on Japanese house rents and automobiles for the ICP.

After my report was submitted to the UN together with all the other reports from Japan, the project leader, Dr. Irving Kravis visited Japan. I had a chance to meet him during his visit. My director at the time introduced me to him. When I met him, he encouraged me to join the project at first sight. He asked me all of a sudden if I would like to work for the ICP, and I replied "Yes, I would be happy to" without thinking too much. It was surprisingly a short and simple interview for me before joining the UN. When I heard the news about a month later that I was accepted, I couldn't believe it. But anyway, I was seconded to the UN Statistical Office for three years starting in June 1978. This is how a Japanese civil servant became an international civil servant.

At the UN, I worked for the ICP as an 'Associate Statistician.' The UN Statistical Office was composed of statisticians from many countries, perhaps around 200 , but there were only three other Japanese. In connection with my work for the ICP, I wrote to many national statistical offices to request necessary data or make inquiries about the data. It was an interesting change of my position from submitting reports and data to the UN to requesting them from national statistical offices. In those days, it took quite long to get replies, because there was no internet or e-mail, and writing letters was a bigger task than now. Just to make simple inquiries to national statistical offices could easily take a few weeks or even more than a month to get replies.

Interviewer: So now you got to experience living on the East Coast of the United States. What differences did you notice? Were there more similarities in the climate between Tokyo and New York than Tokyo and Southern California?

The climate of Tokyo is something in between the two areas. Tokyo is not as cold as New York in the winter, and it is not as warm as Southern California. In Tokyo, it rarely gets below the freezing point in winter. My wife and I loved the Brooklyn Botanical Garden in New York. The cherry blossoms there were very beautiful in spring. We used to visit the Garden from time to time.

Interviewer: Of course, we understand what you are talking about because thanks to the generous gifts from your people to our country, we get to experience the beauty of the cherry trees every spring here in Washington, DC. I can understand if that made you feel a little bit homesick. 
We did enjoy cherry blossoms in the spring in Washington. But not just that. I was impressed that many more Japanese things were available in the U.S. than about ten years before when I was an exchange student. The reason why I felt so could be because New York is the most international city in the world. My wife and I could get all the ingredients needed for Japanese recipes in the grocery stores in the neighborhood, although the prices were about twice as high as in Japan. We enjoyed Japanese food at home, and we also enjoyed food of different nationalities when we ate out. We occasionally went to museums, operas and concerts. We enjoyed our time in New York.

Interviewer: You eventually returned to Japan. From 2007-2011, you served as the Director General of the Statistics Bureau. Statistical leaders throughout the world, but especially in countries that are building their statistical capacity, are interested in learning how a statistical agency can support economic development. Could you give the readers a brief history of Japan's official statistics?

The development of official statistics in Japan owes very much to international exchange. In the middle of the 19th century, Japan began modernization and learning from Western science. One of the fields was statistics.

It was difficult to translate the concept 'statistics' to Japanese. There was no Japanese word in those days that represented the literary meaning of 'statistics.' The word 'statistics' derives from the word 'state', meaning 'science of the state.' No single Japanese word had the same or similar meaning or nuance in those days. Instead, they decided to borrow an old word 'TOKEI', having an origin in the Chinese language, which simply means 'total' or 'aggregation'. That came to be used as the Japanese word for statistics. It has no connotation with 'state'.

Since then, many foreign textbooks on statistics were translated into Japanese. Books from, say, the Netherlands, Great Britain and Germany were translated, and gradually the term of 'TOKEI' became a common word in Japan.

Statistical literature in Japanese was further translated into Chinese, and the same word as 'TOKEI' came to be used in China to mean 'statistics'. Korea and Vietnam also came to use the word having the same origin in their own languages for 'statistics.' Just by looking at the way the word 'statistics' was translated into different languages, we can see how the science of statistics was disseminated across countries.
In 1887, Japan established the first statistical office for the government. It was a very small office. Then, around the turn of the century, the International Statistical Congress (ISC) made a recommendation that every country should conduct a population census in 1900. The ISC is the predecessor of the present World Statistics Congress of the International Statistical Institute. Japan tried to follow the recommendation and worked hard to get the necessary funding for that, but it was difficult under the tight financial conditions of those days. So, the plan was postponed, and the first modern population census was conducted in 1920 .

The Japanese statistical system continued to develop after that. But then, a very unfortunate period for statistics occurred from the late 1930s to the first half of the 1940s. Due to the war, most of the official statistics were not disclosed to the public. Even the Statistical Yearbook was kept confidential. When I recently saw the Yearbook of those days for the first time, I was really surprised to see a big stamp of 'Secret' on the cover page. It is unthinkable nowadays.

After the end of WW II, in 1945, there was a deep critical reflection over production and dissemination of official statistics during the war period. Prime Minister Shigeru Yoshida recognized the importance of official statistics for economic growth and social development, and led the reform of the statistical system. Incidentally, my parents took my name, Shigeru, from him. He was highly admired by the people in those days.

In 1946, a mission of American statisticians led by Stuart Rice visited Japan. At the time, Stuart Rice was the Director of Statistical Standards of the US Government. (Katherine Wallman, Chief Statistician of the United States, now heads the successor office 3 ) The purpose of the mission was to give advice and recommendations on reform of the statistical system and on its statistical methods. One of the important recommendations of the mission was to start using scientific sampling for data collection. Application of sampling in social and economic surveys was still new in those days in the world, and the United States was the leader in using sampling for official statistics. Following the recommendations, Japan began using random sampling for statistical surveys ahead of many other countries in the world, earlier even than some European countries. The first random sample survey was the monthly labor force survey in 1947, and we now have a time series of data dating back to 1953 . We owe

\footnotetext{
${ }^{3}$ Her office is located in the Office of Management and Budget, which is part of the Executive Office of the President.
} 
this outcome very much to the recommendations and advice from the U.S. mission.

It is interesting that there was a by-product of the mission that contributed to the further development of statistics in Japan, not just official statistics, but also statistics applied in industries. Edwards Deming was among the mission members, a very prominent member. He was working at the U.S. Department of Agriculture in those days. Besides his interactions with official statisticians, he worked with the business leaders of Japan - teaching quality control to Japanese industrialists. In those days, Japanese products exported to foreign countries were notorious for being cheap and low quality. So, he gave lectures on statistical quality control methods. The industrialists were strongly impressed, and they studied statistical quality control diligently, and put it into practice in many factories. It made a dramatic change in the quality of Japanese products, and Japanese industries gained international competitiveness. Later on, Japanese products increased their market shares sharply in America and Europe, and trade negotiations between governments were started in the 1980 s to protect other countries' domestic markets.

Deming was so highly respected in Japan for his contribution to Japanese industries that industrialists initiated the Deming Prize, named after him to recognize companies and individuals that achieved excellence in quality control and made significant contributions to the development of quality control methods. Later on, in the 1980s, many American companies came to be more interested in quality control, and they started looking to Japanese industries to learn quality management methods. The U.S. Government initiated the Malcolm Baldrige National Quality Award to encourage quality management in U.S. industries in the late 1980's. It is interesting that countries are learning from each other, taking turns over a long period in leading those efforts.

Anyway, this is how statistics was introduced and developed in Japan. I can give more background stories, but basically, the present Japanese statistical system had its foundation established in the post-WW II period. I am sure other countries also have interesting stories of introduction and development of statistics.

The improvement of statistics continues. From the 1980 s to the early 2000 s, we exchanged experiences with other countries much more than before, and it contributed to improvement of statistics. Advances in census methodology, the consumer price index, and business survey frames are examples.
Interviewer: Let us move on and move up in time and talk about your personal experiences as the Director of the Statistical Bureau. What were some of the biggest challenges you faced during your time in office?

It is difficult to choose, but one important issue that remains in my mind is the 2010 Population Census. We were having difficulty gaining cooperation from the citizens, and at the same time we had to streamline the census. We had to achieve higher efficiency and better data quality. To improve quality, we needed a larger budget than before, but it was difficult to increase the budget under the tight financial situation of the government. Unfortunately, 2010 was a tough year for most government offices, because of severe scrutiny of the budgets of large-scale projects. Many projects were selected for the scrutiny process, and the Director-Generals in charge were invited to a debate at the Scrutiny Committee, and had to respond to the questions they asked. The debate of the scrutiny process was broadcast on the internet for nation-wide public viewing. The 2010 Population Census was included as one of the targets. I still have an impression that the scrutiny had predetermined conclusions in most cases, and many projects got severe budget cuts regardless of how the Director-Generals responded. In my case, I think I responded to all the questions quite well, because I studied various cases of censuses in foreign countries and I was able to justify the census plan clearly, referring to the experiences of other countries. We ended up with a minor cut in the budget. It became possible to begin using internet response in the census for the first time. I was happy to have some phone calls and emails from my friends who watched the scrutiny process, congratulating me on successfully defending the plan.

Japan has a large population - 128 million in 2010 , about 40 percent that of the United States. While we wanted to apply new technology in the census, there were many obstacles from a practical perspective. Introducing an internet system for a huge population is quite risky. For 2010, we decided to apply the system only to the metropolitan area of Tokyo, which has about one tenth of the total population of Japan. That is still a large population, considerably larger than the population of Sweden, for example. It was a big challenge for us. Nearly six million households would access the system just after the census date, which would create a heavy peak load for the system. We had to make the system highly reliable and resilient. If the system should fail, trust in the census would be lost, 
and it could have negative effects even on paper-based responses. In the end, we had no major problems, and we found we were successful. I was very happy about the implementation of the internet system in the 2010 Census. In the next round of the census, in 2015, use of the internet will be broadened to cover the whole country, which was greatly assisted by partial use in the 2010 Census.

\section{Interviewer: So in Japan you take a census every} five years?

Yes. We do.

Interviewer: Do you recall the internet response rate?

It was 8.5 percent. That is not too low for a first trial, but not very high compared with other countries. One of the reasons was that it was very difficult to publicize the internet option sufficiently. We had to concentrate the publicity campaign in the Tokyo area, not across the country. And in order to avoid misunderstanding and too many complaints from people outside Tokyo about not being able to use the internet response system, we had to limit the scale of the campaign. However, the pick-up rate in Tokyo was high enough to conclude that we should expand using the internet to the rest of Japan.

Interviewer: Do you have a mail-out/mail-back census or do you have interviewers going door-todoor?

In our census, enumerators visit each household to confirm its existence in each location. It's very difficult for us to produce an accurate and up-to-date address list just before the census date at a reasonable cost. So, the mail-out/mail-back method cannot be used.

Interviewer: At the end of 2011, you retired from the civil service. You are now teaching economic statistics at the Nihon University in Tokyo. When you think back on those years in the civil service, what are some of your proudest achievements?

The work in official statistics is done by the organization or the staff as a whole, and I have nothing particular to give as something I personally take pride in.

But as I look back, what I feel happiest about is the full revision of the Statistics Law in 2007. This was achieved by the cooperation of many people, and I am happy that I could play a part in it.

The old Statistics Law was enacted in 1947, less than two years after the end of the war. That Law remedied the deficiencies of the pre-war statistical system and practices, and included important clauses such as requiring all statistics to be published, individual information to be kept confidential, and responses to censuses and important surveys to be mandatory. It set the fundamental principles and rules of official statistics of Japan for more than half century. However, as time passed by, many new deficiencies were observed, but it was quite difficult to initiate the revision process. The existence and the value of the Statistics Law was not widely understood or appreciated, and it was not a matter of high interest for politicians. So, it was very difficult to gain political support for revising it. But a good opportunity for revision came up in 2004, and we started working on the revision. Fortunately, the draft revision was well received by politicians, too, and it was passed by the Parliament in May 2007.

Interviewer: Let us also talk about your achievements as an educator. You have been teaching since your retirement three years ago.

I have to admit I don't have an achievement to be proud about as an educator yet, because I am still learning to be a university professor. But of course, I enjoy teaching my students. I not only teach statistical theories, but also try to familiarize the students with real official statistics. I want them to understand how statistics are produced and how they should be analyzed and used. I want to show my students how they can get the information and use it in the real world. I am happy to see students learning statistics with enthusiasm. Currently, my job as IAOS president probably takes up about one third of my energy. The rest goes to the university and teaching.

Interviewer: Tell us about your involvement with professional associations and the IAOS. For you it began in 1985 when you first attended an International Statistical Institute (ISI) session. What prompted you to attend that meeting?

As you said, I have had almost thirty years of involvement with the organization. I did not realize it was that long! I attended the $45^{\text {th }}$ ISI Session in Amsterdam for the first time, which is now called the World Statistics Congress (WSC). Japan sent a delegation, and I was a member. It was necessary, because the Japanese government was to host the $46^{\text {th }}$ ISI Session in Tokyo in 1987 . We were to observe the way the conference was organized and managed, so that we could prepare for the next session.

In 1987, at the $46^{\text {th }}$ Session in Tokyo, the IAOS was founded. But I was not too much aware of it at the time, 
because I was very busy with my work as a member of the conference secretariat. I became an ISI elected member in 1996 and also a member of the IAOS. In the beginning, I did not contribute much to the ISI and IAOS, but I attended the ISI Sessions occasionally to present my work. I did not have an opportunity to attend IAOS conferences. As I repeatedly attended the ISI conferences, I got to know statisticians from many other countries.

In 2011, I received a sounding from the Nominating Committee asking me if I would accept nomination as the next IAOS President-Elect. At first, I hesitated, as I knew I was to retire from the civil service by the end of the year. But it turned out not to be a problem. I thought it over, and decided I should gratefully accept it. I felt that I had received so much from the IAOS and the international statistical community over a long period and that it should be my turn to reciprocate. But I was not too sure if I would be the right person and if I could do it well. All I could say was that I would do my best. That is how I came to assume this position.

Interviewer: Could you talk a little bit more about the value of international cooperation in official statistics?

I want to emphasize the importance of international cooperation in official statistics from my experiences at the Statistics Bureau. This is not just about the IAOS, but involves broader international cooperation. To give some examples:

i) Improving the population census

ii) Enhancing the reliability of the Consumer Price Index

iii) Outsourcing statistical operations to the private sector

iv) Advancing a statistical system by international comparisons

Let me elaborate on some of these examples. First, the population census. Japan has a long history of using advanced technology for data capture. We started using optical mark readers (OMR) in 1970, which was perhaps the first in Asia. We worked closely in the 1970s and the 1980s with other Asian countries to improve their censuses. We began to have regional meetings to share experiences among countries. Several of my colleagues visited other Asian countries and gave them advice on how to improve their censuses.

In 1980 and again in 1990, I visited the U.S. Census Bureau to observe its census operation. I was very much impressed by FOSDIC, for example 4 From observing FOSDIC, I thought we should have an image capture function on the OMR. In the end, we were successful in developing a new OMR system with image capture functions at a reasonably low cost. So that is an example of how exchange of information can help countries improve their censuses.

With regard to the Consumer Price Index (CPI), in the middle of the 1990s, a strong argument was presented in the United States that the CPI was biased upward, accelerating the increase of the federal deficit. The Boskin Commission was appointed by the U.S. Senate, and it concluded that the U.S. CPI overstated inflation by about 1.1 percent per year 5

I knew by experience that what was a hot issue in the United States would usually be imported to Japan sometime later. It was a warning signal for Japan. I thought the Japanese CPI would be subject to the same kind of criticism. I studied this issue in detail, including the reactions of the U.S. Bureau of Labor Statistics (BLS). Then, as I expected, a few years later the same discussion was raised in Japan for the Japanese CPI. At first, there were some criticisms based on misunderstanding, but over time, more appropriate understanding prevailed. In this process, I found what we learned from the experiences in the U.S to be very helpful.

According to our studies on the U.S. and the Japanese CPI, there was a difference in methodology, and not all the arguments about the U.S. CPI applied to the Japanese situation. We could make that case. By sharing this type of information and learning from other country's experiences, we could give appropriate comments in case questions arose regarding the credibility of the Japanese statistics.

Actually, the Boskin report influenced many other countries too, not just the U.S. and Japan. Many European countries also stepped up research on their CPIs. The UN Statistical Commission established an international study group on the CPI called the Ottawa Group, which meets once a year. Japan joined it, and we participated in discussions. I think this kind of international cooperation improved the understanding of the CPI and also improved trust in the quality of the CPI.

\footnotetext{
${ }^{4}$ FOSDIC stands for Film Optical Sensing Device for Input to Computer. It was first introduced in 1954 and continuously improved. The U.S. Census Bureau used updated versions of FOSDIC for the 1970, 1980 and 1990 censuses. FOSDIC was replaced in Census 2000 when optical character recognition was used.

${ }^{5}$ In 1995, the U.S. Senate appointed the Advisory Commission to Study the Consumer Price Index chaired by Michael Boskin. The Commission was called the Boskin Commission. Its report was issued in December 1996.
} 
Next, I would also like to talk about outsourcing of operations of official statistics to the private sector, which emerged in the early 2000s. This issue was raised by the Deregulation Commission of the government with an aim to achieve efficiency of government services. When it came up, I feared it would lead to negative effects on quality and on the efficiency of producing official statistics.

This scheme in Japan was a copy of 'market testing', which was invented in the 1980s in the U.K. under Mrs. Thatcher's administration. Under the scheme of 'market testing', government services were put to open tendering, and the government agencies in charge of providing the services were to bid for contracts in competition with the private sector. If a private service provider wins, the government agency in charge would have to be disbanded. If the government agency wins, it would be able to continue to provide the services within the amount they claimed in the bidding. In this way, it was expected that the cost of providing government services would be lowered to the market price.

Japan became interested in following this system more than ten years after the U.K. Some Japanese politicians were enthusiastic about the idea, and strongly advocated the scheme. They even raised the census enumeration as a possible task to which 'market testing' should be applied.

That was an unthinkable choice to me. It would be almost impossible to maintain trust and the quality of official statistics if such sensitive work on a huge scale were fully outsourced to the private sector. Also, if competitive tendering were to be applied to the government statistical services, it would add a heavy extra work load to the Statistics Bureau, such as writing detailed tender documents, interacting with tenderers, monitoring the quality of work, etc. I thought it necessary to resist this movement. However, it was very difficult to do so, because 'market testing' was gaining strong political momentum.

As I knew there were similar movements in the U.K. and the U.S., I tried to gather information from my friends at the U.K. ONS and the U.S. Census Bureau. They kindly provided me with valuable advice and we were able to strengthen our argument for persuading those people who were advocating this movement.

I don't mean I am totally against using the private sector for government statistical services. What I mean is we should carefully think how to use the private sector appropriately. It would be all right and acceptable to use it in a limited field where the private sector can achieve efficiency while maintaining quality. But
I think it is extremely difficult, if not impossible, and very risky to apply it to sensitive areas such as enumeration and processing of confidential data. I don't know if the outsourcing of government services is a worldwide movement, but I raise this issue as something potentially harmful if it is not properly dealt with. Maybe in the long run we should have some kind of guidance on how to use the private sector in statistical operations properly.

I take it as an important lesson for official statistics, because politicians quite often come up with new ideas and try to force such ideas on statistical offices without thinking of feasibility. Political voices are often very strong, and we have to carefully deal with those new ideas from politicians, assessing the merit and feasibility objectively. How to maintain appropriate relationships between statisticians and politicians is a very delicate issue. To secure resources and improve the legal framework, we have to gain political support. On the other hand, interventions from politicians about the methodology, not to mention the content of statistics, are quite harmful, even if they are based on good intentions. To avoid unnecessary frictions and conflicts with politicians, the Fundamental Principles of Official Statistics is very helpful. How they are applied may depend on conditions in the countries, but we should promote better understanding of them.

Because official statistics are produced only within the government, there are usually few counterparts to learn from within one country. It is easier to find colleagues and counterparts in foreign countries than within your own country. You cannot make full-scale experiments of census taking within one country, but experiences of other countries using different methods can be regarded as large-scale experiments. So, we have much to learn from each other. We can improve statistics by learning from the experiences of other countries, and by presenting our own experiences to them. It is through this process that official statistics develops and grows over the long term.

I hope these examples illustrate the value of international cooperation in official statistics.

Interviewer: As you stated, we could talk about this topic for a long time. There is a lot of material to cover. However, before we conclude the interview, can you share your vision for the IAOS and the Journal?

That is a big question, and I am still searching for the best answers. Let me give you a tentative version, because I am still looking for the answers. But I will try. 
I think the IAOS should pay attention to the change of its relative position in the international statistical community from the time it began. When it was founded, there were not as many international meetings on official statistics as now. I remember that the number of international meetings I could participate in from Japan was very limited. Because of the scarcity of meetings and the lack of travel funds (international travel was relatively more expensive), the opportunity for networking with statisticians from other countries was very limited. The IAOS and ISI Conferences filled that unmet need and had stronger influence then.

But now, international organizations such as the UN, governments, and professional associations host many meetings with specific or broad themes. The UN is much more active than before in holding international meetings. For example, the side events of the UN Statistical Commission serve as valuable forums for official statistics, open to all countries, not limited to the members of the Statistical Commission, covering emerging issues or special issues that have to be explored, such as 'Big data' and 'fundamental principles of official statistics.' The Commission consists of 24 member countries, but nowadays almost all countries of the world participate in the meetings and side events as observers. Other international and national organizations hold many thought-stimulating conferences all over the world. So, compared to the days when the IAOS was founded, there are many high profile conferences to attend besides the IAOS's. Because of these increasing opportunities, the 'scarcity value' of the IAOS meetings seems to be diminishing.

The IAOS has to find where to position itself appropriately. We have to differentiate ourselves from other international organizations, and should figure out how we can complement what they offer.

On the other hand, the IAOS has quite limited resources. Its annual budget is far, far smaller than the UN Statistical Division or a National Statistical Office. The work of the IAOS is performed by a small number of members, such as the President, the Executive Committee members, the SJIAOS Chief Editor, and a few other members having special roles. They are all working voluntarily, in addition to their own jobs.

To achieve the goals of the IAOS, it is necessary to have cooperation from more people to support its activities. Even small contributions can have valuable effects if they come from many people. For this purpose, we need to strengthen the membership basis, and engage more members in the IAOS. Of course, some members are too busy with their own work, and it is not easy for them to share their time. However, even a small amount of support from many members will surely strengthen the IAOS. I also plan to continue inviting many people to join the IAOS, and ask current members to encourage their friends and colleagues to join.

To promote official statistics effectively, the IAOS must involve both producers and users of statistics. Involvement of users and non-official statisticians is becoming more important in developing official statistics. We should extend the scope of official statistics and develop partnership with non-official statistical organizations. From this viewpoint, the IAOS has to take advantage of the fact that we are an international professional association for official statistics, not part of a government, or an international organization of governments. Our membership covers nongovernment statisticians, such as users and educators, as well as official statisticians. So, we can address issues that official statistical organizations, both national and international, might find difficult to tackle. We hold conferences open to all individuals, regardless of official or private status. Anyone, including nonstatisticians, can join us as long as they are interested in official statistics. We accept all disciplines. Interest in statistics is all that matters.

\section{Interviewer: And this is where the vision for the} Journal might come in?

Yes! A statistical journal is a big undertaking, and it's a big task to edit and publish a journal issue of high quality every quarter. We have had many excellent editors in the past. Unfortunately, the previous editor passed away unexpectedly in 2012 during his tenure. Dr. Fritz Scheuren took over as the Chief Editor in April 2013. I am impressed by his tremendous contribution and dedication to strengthen and improve the Journal. He finds good authors, and encourages them to write papers for the SJIAOS, and has improved the quality of the journal considerably. The IAOS strongly supports the Chief Editor and the editorial board and I commend Fritz for his excellent initiatives.

One thing I became better aware of in exchanges with Fritz is that the SJIAOS is more than a journal to disseminate knowledge and insights of the authors to the statistical community. It is also an important tool for promoting the IAOS to the statistical community, which in turn promotes membership in the IAOS. We have to create synergy among different activities of the IAOS including the SJIAOS.

For example, at the initiative of Fritz, we have introduced free IAOS membership for one year for non- 
members who are first-time contributors to the Journal. If a non-member publishes a paper in the Journal, he or she will receive one year of free membership, which automatically includes free access to the SJIAOS. What we hope to do is to raise an interest in the Journal as well as the association. I want to invite members to provide more suggestions for publicity and a membership drive. There may be more ideas to make one plus one more than two!

Thank you for the opportunity to talk about myself and my views. This has been a wonderful opportunity for me to think about myself and the IAOS, and I enjoyed talking with you.

The telephone interview of Mr. Shigeru Kawasaki took place in November 2014. Kirsten West and Katherine Condon conducted the interview.

Kirsten West is a demographer at the U.S. Census Bureau. Her area of expertise is population estimation and census coverage measurement. She has worked on the 1990 Post-Enumeration Survey, the 1991 Evaluation Survey, and the 2000 and 2010 Demographic Analysis operation. She holds a Ph.D. from the University of North Carolina at Chapel Hill.

Katherine Condon is a demographer/sociologist at U.S. Citizenship and Immigration Services (USCIS) Office of Policy \& Strategy. She holds a Ph.D. from Florida International University (Miami, FL) in Sociology and Anthropology and has a Masters (and is ABD) from University of Pennsylvania (Philadelphia, PA) in Demography. Prior to joining USCIS, she worked at the U.S. Census Bureau in the Population Division's Population Estimates and Projection Area's Administrative Records and Methodological Research Branch, as well as in the Decennial Programs Area.

Kirsten West E-mail: kwestiaos@gmail.com 